ORIGINAL ARTICLE

\title{
CD56: a useful tool for the diagnosis of small cell lung carcinomas on biopsies with extensive crush artefact
}

\author{
K Kontogianni, A G Nicholson, D Butcher, M N Sheppard
}

J Clin Pathol 2005;58:978-980. doi: 10.1136/icp.2004.023044

See end of article for
authors' affiliations
$\ldots \ldots \ldots \ldots \ldots \ldots \ldots . \ldots . \ldots$.
Correspondence to:
Dr M Sheppard,
Department of
Histopathology, Royal
Brompton Hospital,
Sydney Street, London
SW3 6NP, UK'
m.sheppard@rbh.
nthames.nhs.uk
Accepted for publication
18 January 2005

....................

\begin{abstract}
Background/Aims: The diagnosis of small cell lung carcinoma (SCLC) on bronchial biopsy is often problematical as a result of intense crush artefact. Several antibodies are now available to help in the diagnosis of SCLC and their value was assessed in this clinical situation.

Methods/Results: Twenty cases of SCLC and 10 control cases (one non-Hodgkin lymphoma, three nonsmall cell carcinomas, one follicular reactive hyperplasia, and five chronic non-specific inflammations) with extensive crush artefact were stained using antibodies to CD56, MNF1 16, thyroid transcription factor 1 (TTF-1), and CD45. All SCLCs showed strong positive staining for CD56 in 75-100\% of recognisable tumour cells, even in areas where there was extensive crush artefact. Eighteen of 20 cases were positive for TTF- 1 and 16 of 20 were positive for MNF1 16 in the tumour cells, but both of these antibodies showed little or no staining in areas of crush artefact. Control cases comprising lymphoid cells were positive for CD45 in areas of crush artefact, but all cases of SCLC were negative.

Conclusion: CD56, along with markers for cytokeratins - TF- 1 , and CD45-are useful in the diagnosis of SCLC in biopsies with extensive crush artefact and can help confirm the diagnosis in cases where features are equivocal.
\end{abstract}

$M$ ost pulmonary carcinomas are readily classified into small cell carcinomas or non-small cell carcinomas in small biopsies, based on morphological features such as cellular pattern, cell size, nuclear to cytoplasmic ratio, and nuclear features such as chromatin pattern and the presence or absence of nucleoli. ${ }^{1}$ Small cell carcinoma is typically a lesion of central regions of the lung and bronchoscopic biopsy is often positive.

"The diagnosis of small cell carcinoma remains problematical when biopsies are small and crushed, a not uncommon feature in this type of tumour because of the fragile nature of the tumour cells"

Morphological data to confirm the diagnosis of small cell carcinoma are increasingly supported by immunohistochemistry using cytokeratins and neuroendocrine markers, such as chromogranin A, CD57 (Leu-7), synaptophysin, neurone specific enolase, ${ }^{2-4}$ and most recently CD56. ${ }^{56}$ Indeed, CD56 has become the antibody of choice in many laboratories because the sensitivities for other antibodies in small cell lung carcinoma vary, ${ }^{7-11}$ and comparative studies suggest that CD56 is the most sensitive marker in this context. ${ }^{56}$

However, the diagnosis of small cell carcinoma remains problematical when biopsies are small and crushed, a not uncommon feature in this type of tumour because of the fragile nature of the tumour cells. ${ }^{10}$ Therefore, it would be useful to know the sensitivity of antibody expression when morphology is obscured. To this end, we have investigated a cohort of small cell lung carcinomas with extensive crush artefact in which a minority of the cells had the definitive morphological features of small cell carcinoma, using antibodies to CD56, MNF116, and also thyroid transcription factor 1 (TTF-1) - a recently available antibody with high sensitivity for pulmonary small cell lung carcinomas $^{12}{ }^{13}$ - to assess their usefulness in confirming the diagnosis.

\section{MATERIALS AND METHODS}

Twenty cases in which only a minority of cells displayed the typical salt and pepper nuclei, nuclear moulding, mitoses, and apoptosis typical of small cell carcinoma, and in which most of the biopsy had crush artefact, were identified from the archives of the department of histopathology of the Royal Brompton Hospital from January 1989 to February 2003.

One case of non-Hodgkin lymphoma, one case of reactive follicular hyperplasia, three cases of non-small cell carcinoma, and five cases of chronic, non-specific inflammation, all of which had extensive areas of crush artefact, were used as a control group. This control group is small because of the paucity of documented biopsies where crush artefact was high making the differential diagnosis with small cell carcinoma difficult.

All cases had been classified according to the World Health Organisation/IASLC classification for lung tumours. ${ }^{14}$

Formalin fixed, paraffin wax embedded blocks were selected from each case for immunohistochemical studies. Automated immunohistochemistry based on the streptavidin-biotin system labelled with peroxidase was used to characterise the expression of CD56 (antibody diluted 1/100; Novocastra, Newcastle upon Tyne, UK), TTF-1 (antibody diluted 1/80; Dako, Cambridge UK), MNF116 (antibody diluted 1/50; Dako), and CD45 (antibody diluted 1/100; Dako) in all cases. High temperature (pressure cooker) antigen retrieval in citrate buffer was required for CD56, TTF-1, and MNF116, but was unnecessary for CD45.

Immunostaining scores were established for all four antibodies. Staining was considered strongly positive $(++++)$ when $>75 \%$ of the viable and crushed cells showed positive staining; positive $(+++)$ when $>50-75 \%$ of viable and crushed cells showed positive staining; moderately positive $(++)$ : when $25-50 \%$ of viable and crushed cells showed positive staining; and weak $(+)$ when $<25 \%$ of viable and crushed cells showed positive staining.

Abbreviations: SCLC, small cell lung carcinoma; TF-1, thyroid transcription factor 1 

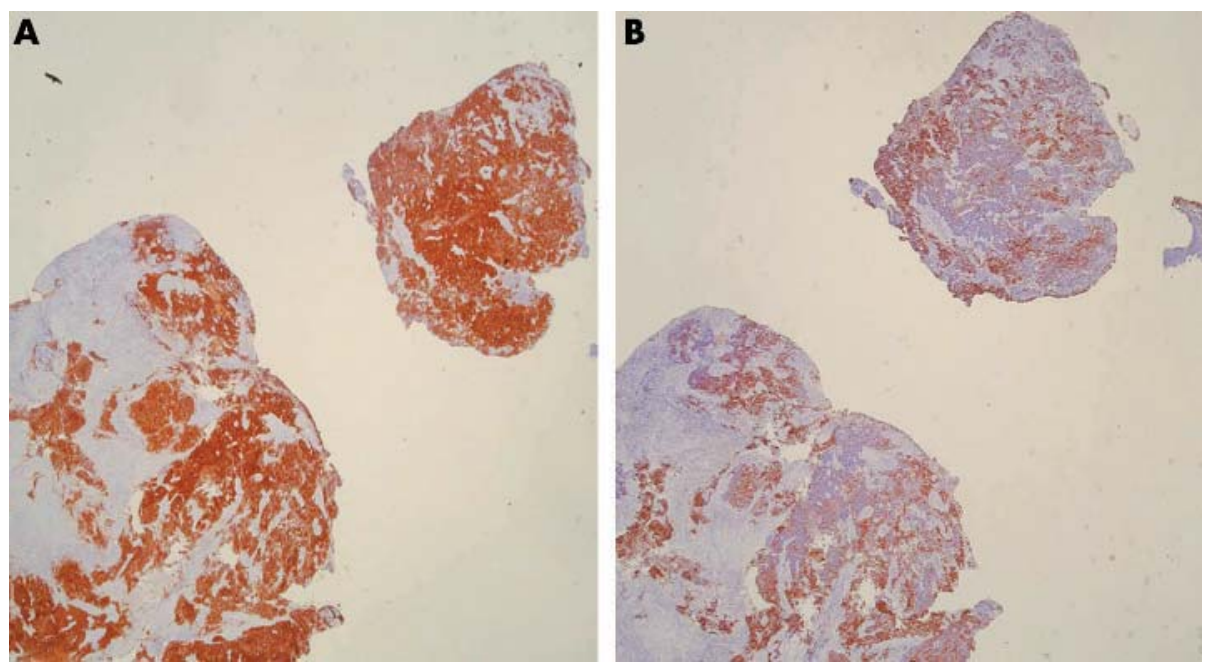

Figure 1 (A) Bronchial biopsy showing extensively crushed cells staining diffusely for CD56. (B) Same bronchial biopsy showing positive staining for MNF1 16, although the extensively crushed cells show variable or little staining.

\section{RESULTS}

\section{Clinical features}

There were 14 male patients, aged from 52 to 81 years (mean, 67.36), and six female patients, aged from 58 to 86 years (mean, 70.2).

There were three lymph node biopsies, 16 bronchial biopsies, and one mediastinoscopy.

\section{Immunohistochemistry}

All SCLCs were strongly positive for CD56. Anti-CD56 showed a strong pattern of cytoplasmic staining in $75-100 \%$ of tumour cells, even in areas of crush artefact (figs 1, 2).

Eighteen of 20 cases were moderately to weakly positive for TTF-1 within the nuclei (fig 3), but staining was often more heterogeneous and focal than for CD56, ranging from $25 \%$ to $50 \%$ of tumour cells. Areas of crush artefact were typically negative. Sixteen of 20 cases were also moderately or weakly positive for MNF116 (fig 1B); variation of staining was seen, as for TTF-1, with crushed areas often being negative. All cases were negative for CD45. Both seromucous glands and nerve bundles in biopsies also expressed CD56, whereas surface epithelium in bronchial biopsies was negative.

In the control group, CD45 was positive in lymphoid aggregates, whereas in one case atypical cells stained for CD45 and further immunohistochemistry confirmed a nonHodgkin B cell lymphoma. Three cases of non-small cell

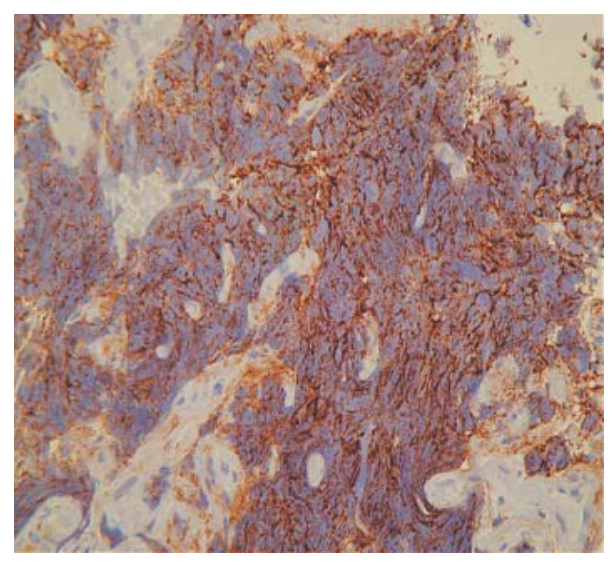

Figure 2 Bronchial biopsy showing extensively crushed cells staining diffusely for CD56. carcinoma were positive for MNF116, but only weakly positive for $\mathrm{CD} 56$, indicating that these were large cell neuroendocrine carcinomas, whereas TTF-1 was positive in one case.

\section{DISCUSSION}

The diagnosis of SCLC is most often made on small biopsies and cytological specimens. Practising pathologists may not to be familiar with all its morphological guises. Frequent artefacts and difficulties in interpretation may arise from inadequate fixation, suboptimal processing, "bubbling", crushing, squeezing, dyscohesion, and necrosis, making the diagnosis of SCLC and its distinction from other malignancies, particularly lymphoma, very difficult. ${ }^{10}$

\section{"Haematoxylin and eosin stained slides need to be interpreted along with the immunostaining to come to a firm diagnosis of small cell lung carcinoma"}

Neural cell adhesion molecules are specifically expressed by neural, peripheral neuroectodermal, and neuroendocrine tissues and tumours. They belong to the immunoglobulin family of cell surface adhesion proteins involved in direct cell-cell adhesion. ${ }^{15-17}$ CD56 or neural cell adhesion molecule is also found in natural killer cells, natural killer-like T cells, myocytes, and seromucous glands. ${ }^{18}$

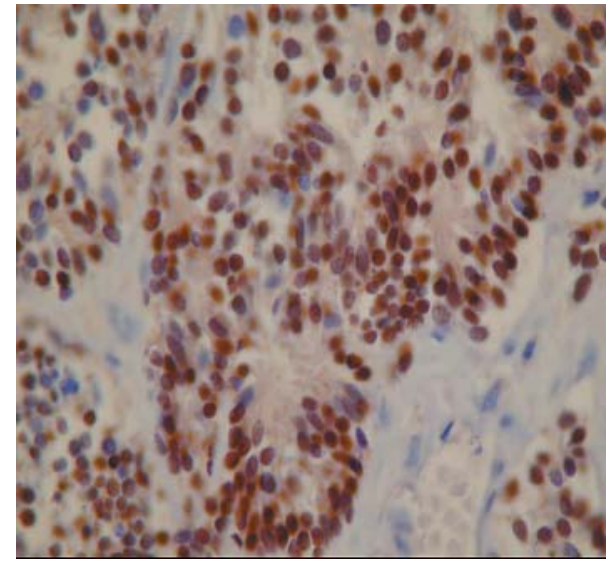

Figure 3 Small cell carcinoma cells showing positive nuclear staining for thyroid transcription factor 1 . 


\section{Take home messages}

- Immunohistochemistry for CD56, thyroid transcription factor 1, and CD45 is useful in the diagnosis of small cell lung carcinoma in biopsies with extensive crush artefact

- Combined with histology, these antibodies can help confirm the diagnosis in cases where features are equivocal

In our study, we tested the use of CD56 neural cell adhesion molecule as a diagnostic aid for the immunohistochemical diagnosis of SCLC. CD56 showed a strongly diffuse cytoplasmic staining in all SCLC in our series, even in badly crushed biopsy specimens. CD56 showed a uniform strong staining pattern in SCLC, whereas crushed areas were often negative for TTF-1 and MNF116. However, it is important to realise that CD56 is found in seromucous glands, nerve bundles, non-small cell carcinoma, and some lymphomas, ${ }^{17} 18$ so haematoxylin and eosin stained slides need to be interpreted along with the immunostaining to come to a firm diagnosis of SCLC. Areas of preserved morphology are still needed to be confidant of the diagnosis of small cell carcinoma.

MNF116 stains all carcinomas in the lung, but is usefully combined with CD56 and TTF-1 for distinguishing SCLC from non-Hodgkin lymphoma. ${ }^{19}{ }^{20}$ Non-small cell carcinomas with CD56 staining indicate a neuroendocrine phenotype. ${ }^{21}$

The use of TTF-1 in SCLC has been studied extensively. ${ }^{13} 1920$ TTF-1 has been used to distinguish SCLC from non-pulmonary small cell carcinomas, especially in combination with cytokeratins. ${ }^{12}$ In our study TTF-1 showed moderate to weak positive expression in most cases, and was a useful adjunct to CD56 in the diagnosis of SCLC.

In conclusion, we found that antibodies to CD56, MNF116, and TTF-1 made up a useful panel of immunohistochemical markers for the diagnosis of SCLC in extensively crushed biopsy specimens. This panel is extremely useful combined with histology and should be applied in difficult bronchial biopsies with crush artefact in every day practice.

\section{Authors' affiliations}

K Kontogianni, Department of Histopathology, Areteion Hospital, Athens, Greece

A G Nicholson, D Butcher, M N Sheppard, Royal Brompton and Harefield NHS Trust, London SW3 6NP, UK

\section{REFERENCES}

1 Thomas JS, Lamb D, Ashcroft T, et al. How reliable is the diagnosis of lung cancer using small biopsy specimens? Report of a UKCCCR lung cancer working party. Thorax 1993;48:1135-9.

2 Wilson RS, Lloyd RV. Detection of chromogranin in neuroendocrine cells with a monoclonal antibody. Am J Pathol 1984;115:458-68.

3 Gould VE, Wiedenmann B, Lee I, et al. Synaptophysin expression in neuroendocrine neoplasms as determined by immunocytochemistry. Am J Pathol 1987; 126:243-57.

4 Said JW, Vimadalal S, Nash G, et al. Immunoreactive neuro-specific enolase, bombesin and chromogranin as markers for neuroendocrine lung tumors. Hum Pathol 1985; 16:236-40.

5 Lantuejoul S, Moro D, Michalides RJ, et al. Neural cell adhesion molecule (NCAM) and NCAM-PSA expression in neuroendocrine lung tumors. Am J Surg Pathol 1998;22:1267-76.

6 Kibbelaar RE, Moolenaar CEC, Michalides RJ, et al. Neural cell adhesion molecule expression, neuroendocrine differentiation and prognosis in lung carcinoma. J Cancer 1991;24:431-5.

7 Dardick I, Christensen H, Stratis M. Immunoelectron microscopy for chromogranin in small cell neuroendocrine carcinoma of lung. Ultrastruct Pathol 1996;20:361-8.

8 Walts AE, Said LW, Shintaku P. Chromogranin as a marker of neuroendocrine cells in cytological material-an immunohistochemical study. Am J Clin Pathol 1984;84:273-7.

9 Haimoto H, Takahashi Y, Koshikawa T, et al. Immunohistichemical localization of gamma-enolase in normal human tissue other than nervous and neuroendocrine tissues. Lab Invest 1985;52:257-63.

10 Nicholson SA, Beasley MB, Brambilla E, et al. Small cell lung carcinoma (SCLC): a clinicopathologic study of 100 cases with surgical specimens. Am J Pathol 2002;26:1 184-97.

11 Matsuki Y, Tanimoto A, Hamada T, et al. Histidine decarboxylase expression as a new sensitive and specific marker for small cell lung carcinoma. Mod Pathol 2003;16:72-8.

12 Ordonez NG. Value of thyroid transcription factor- 1 immunostaining in distinguishing small cell lung carcinomas from other small cell carcinomas. Am J Surg Pathol 2000;24:1217-23.

13 Folpe AL, Gown AM, Lamps LW, et al. Thyroid transcription factor-1: immunohistochemical evaluation in pulmonary neuroendocrine tumors. Mod Pathol 1999; 12:5-8.

14 Travis WD, Colby TV, Shimosato Y, et al. Histological typing of lung and pleural tumors. In: WHO/IASLC classification of lung and pleural tumors. Berlin: Springer, 1999:31-4.

15 Rutishaver V, Acheson A, Hall AK, et al. The neural cell adhesion molecule (NCAM) as a regulator of cell-cell interactions. Science 1988;240:53-7.

16 Jin L, Hemperly JJ, Lloyd. Expression of neural cell adhesion molecule in normal and neoplastic human neuroendocrine tissues. Am J Pathol 1991;138:961-9.

17 Molenaar W, de Leij L, Trojanoswski JQ. Neuroectodermal tumors of the peripheral and the central nervous system share neuroendocrine NCAM related antigens with small cell lung carcinomas. Acta Neuropathol 1991:83:46-54.

18 Mechtersheimer G, Staudter M, Moller P. Expression of the natural killer cellassociated antigens CD56 and CD57 in human neural and striated muscle cells and in their tumors. Cancer 1991;51:1300-7.

19 Hanly AJ, Elgart GW, Jorda M, et al. Analysis of thyroid transcription factor-1 and cytokeratin 20 separates merkel cell carcinoma from small cell carcinoma of lung. J Cutan Pathol 2000;27:1 18-20.

20 Cheuk W, Kwan MY, Suster S, et al. Immunostaining for thyroid transcription factor 1 and cytokeratin 20 aids the distinction of small cell carcinoma from Merkel cell carcinoma but not pulmonary from extrapulmonary small cell carcinomas. Arch Pathol Lab Med 2001; 125:228-31.

21 Brambilla E, Travis WD, Colby TV, et al. The new World Health Organization classification of lung tumour. Eur Respir J 2001;18:1059-68. 